\title{
Temporalizing ontology: a case for pragmatic emergence
}

\section{Ludger van Dijk ${ }^{1}$}

Received: 27 September 2019 / Accepted: 28 February 2020 / Published online: 11 March 2020 (c) The Author(s) 2020

\begin{abstract}
Despite an attempt to break with the hierarchical picture in traditional emergentist thought, non-standard accounts of emergence are often still committed to a premise that ontology is prior to epistemology. This paper aims to topple this last remnant of the traditional hierarchy by explicating a pragmatic view of emergence based on John Dewey's work. Dewey argued that the traditional notion of ontology is premised on a view of existence as complete. Through a discussion of Dewey's work it is argued that this premise results in a process of reification that unduly excludes from ontology many precarious and indeterminate aspects involved both in everyday life and in philosophic and scientific inquiry. Building on a recent explication of transformational emergence the paper proposes a diachronic and non-hierarchical account of emergence, called pragmatic emergence. According to that account the relation between ontology and epistemology is a temporally reciprocal one. This means that ontological and epistemological features co-determine each other over time. Determinacy and continuity become historical features of a multitude of unfinished processes that we view from within.
\end{abstract}

Keywords Emergentism · Epistemology · Dewey · Ontology · Pragmatism · Reductionism · Temporality

there is no exclusive one-way exercise of conditioning power, no mode of regulation that operates wholly from above to below or from within outwards or from without inwards. Whatever influences the changes of other things is itself changed. (Dewey 1958, p. 73).

\section{Introduction}

Emergentism aims to do justice to the observation that at higher degrees of organizational complexity, systems exhibit new phenomena (Kim 1999). Think for instance of

$\bigotimes \quad$ Ludger van Dijk

Ludger.vanDijk@uantwerpen.be

1 Department of Philosophy, Centre for Philosophical Psychology, University of Antwerp, Rodestraat 14, 2000 Antwerp, Belgium 
the emergence of life from simpler physical and chemical interactions. The phenomena of life seem dependent on their basic constituents and yet they are also unlike these basic constituents. A central issue in thinking about emergence has been the question of how to conceptualize the determinative relations going "upward" or "downward" from the basic constituent to the emergent phenomenon or vice versa. As this terminology indicates, standard emergentism is, often explicitly, committed to a hierarchical order of nature (Humphreys 1997; Emmeche et al. 1997; Kim 2002).

This paper takes issue with the hidden premise that lies at the base of this hierarchical ordering: the premise that existence is complete or finished. Emergentism can only be a consistent position if neither the "upward" nor the "downward" relation is sufficient on its own (Sartenaer 2016). If the upward relation is too strong the emergent phenomenon may be overdetermined and this would result in a reductionist position. If it is too weak pluralist positions ensue as the emergent phenomenon becomes discontinuous from its base. Needing to walk a fine line between continuity and discontinuity (and between monism and pluralism) the requirement that existence is finished leads to a tension in standard emergentism.

On the one hand, the relation between what exists and our knowledge or experience thereof, i.e. between ontology and epistemology, is itself subject to emergentist considerations. For instance, in exploring the mind-body relation in the philosophy of mind emergentism balances between taking our experience of the world, i.e. the mind, to be reducible to physical or bodily states and taking the mind as radically discontinuous from the physical world (e.g. dualism). On the other hand, in the context of the philosophy of science, ontology is commonly defined as independent of any cognitive organism's epistemic state (e.g. Emmeche et al. 1997, p. 106; Humphreys 2016, p. 761). By conceptualizing ontology in that way, the ontological realm is typically assumed to be prior to epistemology and complete in and of itself.

To alleviate this tension in standard emergentism, I wish to offer a defense of an open-ended ontology. This view will lead me to propose of a non-standard, diachronic and non-hierarchical, flat emergence. With this aim in mind, the paper also wishes to offer a historical correction to the literature on emergentism. While the self-sufficiency of the ontological realm has been identified as a common feature even in modern versions of emergentism (Sartenaer 2016; see below Sect. 2.2), the American pragmatist John Dewey is also hailed as proposing an early emergentist approach to mind-body issues in psychology (e.g. Sartenaer 2016, p. 85; Sawyer 2002, p. 8 ff.). Dewey however insisted that we consider existence unfinished and explicitly defended the view that ontology is not prior to epistemology, but co-determined with it.

At the heart of Dewey's argument is a charge of reification which he called the fallacy of selective emphasis. This fallacy assumes the premise of completed existence and systematically excludes phenomena from scientific curiosity. That is, it excludes the very indeterminate and precarious aspects of life that scientific practice requires to get going. In Sect. 3 I'll take up 'transformational emergence' (Guay and Sartenaer 2016) as a promising new route to emergence and suggest modifying it along Dewey's pragmatic lines. In Sect. 4, I'll argue specifically for a temporal reciprocity between an ontological realm and epistemological phenomena, both unfinished but co-determining together in a relational process. This allows one to consider continuity 
and discontinuity, as well as determinacy and indeterminacies, to relate to each another temporally. Those implications are explored in the final section.

\section{Experience in nature}

John Dewey has been hailed as an early proponent of emergentism in psychology because he noted both the continuity and difference as organismic responses become intellectual (Dewey 1929, p. 220; see Sartenaer 2016, p. 85). A generalized version of this emergentist taste can be found in Dewey (1915) discussing Darwinian thought and the advent of life. Dewey noted that as physical or chemical interactions intensify, grow more complex, and can no longer be predicted easily, they "exhibit capacities not to be found in an exclusively mechanical world" (ibid., p. 345). His point being that genuinely new phenomena $(E)$ can emerge over time from simpler, predictable, interactions $(B)$. Thus, hitting the two criteria for emergence suggested by Guay and Sartenaer (2016), Dewey suggests that:

(DEP) $E$ is dependent on, or determined by, $B$; while

(NOV) $E$ is also novel with regard to, or autonomous from $B$.

Importantly to Dewey the emergence of life from simpler physicochemical interactions does not license us to think that that life was already contained, but somehow unavailable, by its antecedent processes (viz. vitalism). But, perhaps less obviously so, nor does the advent of life on Dewey's view require us to regard $E$, e.g. phenomena of life, as any less basic than its emergence basis, $B$. That is, $E$ is ontologically just as real as $B$ is. $B$ is historically, not hierarchically, prior to $E$ (see ibid., p. 298). If an emergentist, Dewey apparently commits to diachronic not synchronic emergence. As I will show however the inclination to think hierarchically about the relation between $E$ and $B$ to Dewey would stem from what he would later call the 'philosophic fallacy,' or the 'fallacy of selective emphasis' (Dewey 1958; see Dewey 1929, p. 141 ff.). On Dewey's view, a move to diachronic emergence alone is not enough to escape this fallacy.

\subsection{The fallacy of selective emphasis}

The fallacy of selective emphasis, Dewey writes in Experience and Nature (1958), is a "conversion of eventual functions into antecedent existence" (ibid., p. 29). The first problem that the fallacy identifies is one of reification: making (temporal) processes out to be pre-existing, a-temporal, states. Reification is a common phenomenon in science and philosophy and its practice has been criticized numerous times (see e.g. Ingold 1993; James 1890; Harris 1981; Heft 2003; Noble 1981; Shotter 1983; Van Dijk 2016; Whitehead 1925). The second, and distinctive, problem identified through the fallacy is that it selectively reifies only particular aspects of the processes under consideration, and leaving many others untouched. It reifies only the features that give us a sense of grip on our everyday life - useful features of our everyday and scientific practices. A focus on such features may well be a good thing: they allow for some level of control or predictability and may thus offer comfort in the face of the precariousness 
of life. But that does not mean we ought to reify those, let alone only those, features selectively.

The features reified are then those that are relatively reliable in what can be done with them, stably recurring across the process, or apply generally, in that they are identifiable in many different processes. Or reification focusses on those features that allow for predicting or controlling physical phenomena, such as mathematical formalizations or theoretical entities, including natural laws or notions of causation. Think for example of aspects that might successfully guide one in making one's way in a shared and fragile environment, such as optical patterns that correspond to the direction of movement, a stable food source for eating, or the practice of time keeping for coordinating over distances. Only those aspects that are particularly useful or successful in explaining, predicting or controlling a phenomenon are taken to be of interest.

While focusing on useful, predictable or stable features makes practical sense, it may also lead to neglecting inconveniently messy, uncontrollable, fragile or precarious characteristics. Indeed, the fallacy takes the former to be more important or fundamental than the latter. By reifying only the stable and predictable features, the fallacy promotes only those features to a place outside the process in which they were found. They are thus converted into "antecedent existence" (Dewey 1958, p. 29), into what must pre-exist change. Rather than persistent they becomes fixed, instead of reliable they become "necessary." All the while, the indeterminate and fragile are left where they are. As Dewey put it, the fallacy:

supplies the formula of the technique by which thinkers have relegated the uncertain and unfinished to an invidious state of unreal being, while they have systematically exalted the assured and complete to the rank of true Being. (ibid., p. 52)

The fallacy both expresses and propagates a "craving for the sure and fixed" (Dewey 1958, p. 50; see Wittgenstein 1958, p. 17). To Dewey it is the fallacy of selective emphasis, the philosophic fallacy, that separates epistemology from ontology (experience from nature). Through this fallacy the persistent and reliable aspects of ongoing processes are promoted to a-temporal, pre-existing realm of ontology. Transient, unstable features, indeterminacy and fragility, are at the same time demoted to a realm outside of the ontological. Such messy aspects are no longer part of fabric of existence, no longer as real as the rest of the world, but belong to the realm of epistemology instead. Contingencies and precariousness become due to our perceptual shortcomings, or lack of knowledge, while reality itself is already fixed and determinate regardless. ${ }^{1}$

The fallacy of selective emphasis supplies the logic for metaphysical foundationalism. It is not just visible in attempts to reduce the messiness of life to physical states and causal connections, or to formulate laws that smoothly transition from the biological to the psychological domain. It is, as Dewey put it, performed "in behalf of mathematical subsistences, esthetic essences, the purely physical order of nature, or

\footnotetext{
1 Dewey is thus not abandoning ontology, but wants to push back against a particular picture of ontology as a-temporal and already complete. He "converts all the ontological, as prior to inquiry, into the logical as occupied wholly and solely with what takes place in the conduct of inquiry" (Dewey and Bentley 1949, p. 321). I thank an anonymous reviewer for pointing me to this quote.
} 
God" (Dewey 1958, p. 29). Dewey takes care to show how any totalization evidences a view of existence as already complete, ready to be pigeonholed into a system of our choosing. Even philosophers of flux, such as Whitehead, Hegel or Bergson, do not escape the fallacy if they make change itself "universal, regular and sure" (ibid., p. 50 ff.; see Dewey 1937). The fallacy is visible in flights into dialectics, but also in the insistence on laws or causality as a pre-requisite to existence.

For Dewey ontology does not lie outside any process but is itself in process. He had a temporalized and thus open-ended notion of ontology. On that view lawful relations are one continuous outcome of a pragmatic (affording) world. In the midst of a multitude of transformative meetings of materials and skillful scientist, attempts at formalizing, measuring, failures and successes, scientific practices managed to stabilize some phenomena rather than others. By continuing to look for laws and causes we are able to have a more refined experience of the world we live in. But just because a phenomenon is not amendable to natural law, or cannot be understood in terms of causation, should not preclude it from existence. Many aspects of everyday life as well as scientific phenomena may not be captured by such descriptions and more suitable alternatives need to be developed.

\subsection{Hidden foundations}

If Dewey's analysis is right, what would that mean for the notion of ontology at work in modern emergentism? Consider the thesis of "ontological determinism" that lies at the heart of the field today (Sartenaer 2015, p. 42). Ontological determinism is summarized as the claim that there is a "univocal and uniform determinative relationship that links successive states of a given system (or the entire universe) through time" (ibid., p. 43). It means to capture the idea that this relationship (henceforth $U$ ) is sufficient to determine any (future) state at the ontological level. Thus ontological determinism implies that the ontological realm, defined by $U$, is already complete. Indeed, even if the relationship has not proceeded through all its states yet, those states are pregiven with the existence of a univocal and uniform relationship. $U$, in short, acts as the metaphysical foundation, as existing outside time: allowing for change but itself unchanging.

In a pivotal paper by Sartenaer (2015) ontological indeterminism, the claim that there is no such single determinative relationship, is chiefly dismissed because it was "not empirically uncontroversial" (ibid., p. 44). ${ }^{2}$ Only quantum mechanics is taken as a candidate for getting ontological indeterminism started. It takes the measurement to co-determine the behavior of the phenomena under scrutiny. Yet vindicating such a view, according to Sartenaer, requires a methodological approach contested in that field. These considerations suggests that $U$ secondly means to separate epistemology from ontology: if an epistemic process, such as measuring activity, could co-determine the ontological state of the system, then the self-sufficiency of $U$ would not hold. ${ }^{3}$

\footnotetext{
2 A second ground for dismissal of the thesis of ontological indeterminacy was that the thesis would deny the common ground of emergentism and reductionism alike (i.e. agreement on the hierarchical order of nature). One might agree with this assessment without agreeing with the negative evaluation of it.

3 Alternatively, epistemological processes could be assumed to themselves be lawfully determined in $U$. Such a view seems to have a precedent in scientific psychology (cf. Shaw \& Turvey 1999). It however does
} 
Dewey would no doubt agree that determinacy in any domain of inquiry is a thesis that requires empirical argument. But whether the ontological realm is determinate or indeterminate and whether it is prior to epistemological processes can be regarded as separate issues. Dewey can be read as denying the latter and suggesting that ontology is not yet determinate but is, in part, determined in activity. As long as we consider ontology open-ended, any determinacy that we can establish empirically is also ontological determinacy - and so are any indeterminacies we encounter. In the next sections an account of emergence consonant with this view is developed. Assuming the ontological realm is closed under a single "uniform and univocal determinative relation" implies that ontology is not only determinate but also unchanging, given once and for all. Collaterally, or so the fallacy suggests, the assumption defines a place for epistemology by exclusion.

\section{Transformative emergence}

In order to circumvent the fallacy of selective emphasis this section introduces Guay and Sartenaer's (2016) recent non-standard approach to emergence, called transformational emergence. Transformational emergence (henceforth TE) is an exciting new approach to emergence, much more in line with Deweyian thought. Considering a system $S$ at two successive times $t_{1}$ and $t_{2}$ across its unfolding, Guay and Sartenaer (2016), p. $302 \mathrm{ff}$.) propose that the system at $t_{2}\left(S_{2}\right)$ can be said to "transformationally emerge" from $S_{1}$ at $t_{1}$ if and only if there exists a transformation [Tr] such that:

$\left(\mathrm{DEP}_{d}\right) S_{2}$ is the product of a spatiotemporally continuous process going from $S_{1}$ (for example causal, and possibly fully deterministic). In particular, the "realm" $R$ to which $S_{1}$ and $S_{2}$ commonly belong (e.g. the physical realm) is closed, to the effect that nothing outside of $R$ participates in $S_{1}$ bringing about $S_{2}$. And yet

$\left(\mathrm{NOV}_{d}\right) S_{2}$ exhibits new entities, properties or powers that do not exist in $S_{1}$, and that are furthermore forbidden to exist in $S_{1}$ according to the laws $\left\{L_{1}\right\}$ governing $S_{1}$. Accordingly, different laws $\left\{L_{2}\right\}$ govern $S_{2}$ (from ibid., p. 303).

Notice that this way of thinking about emergence explicates the $\mathrm{DEP}_{d}$ and $\mathrm{NOV}_{d}$ claims as issues of continuity. On this view $E$ (here $S_{2}$ ) emerges from $B\left(S_{1}\right)$ through a diachronic determinative relation, the transformation [Tr], that ensured spatiotemporal continuity. Yet the new laws that govern the phenomena in $S_{2}$ are discontinuous with those in $S_{1}$; at least one law of the latter should in fact be inconsistent with those governing the former (ibid.).

Moving away from the petrified metaphysics of standard emergentism, there is much to value in this proposal. It is for instance an example of diachronic emergence, in which $B$ is not logically or metaphysically prior to its $E$, but it is prior in time. It tips the vertical worldview of standard emergence onto its side, so to speak. Consequently, TE is said to be indifferent about hierarchies (ibid., p. 311). Crucially moreover, TE explicitly aims for allowing ontological novelty, for the emergence of new phenomena

\section{Footnote 3 continued}

not avoid the fallacy of selective emphasis. Unable to relegate everyday precariousness and indeterminacy to epistemology, the view appears to have difficulties finding any place for such phenomena, let alone for phenomena that resist lawlike descriptions (see Sect. 4.1). 
with new laws governing them, as systems transform over time. Accordingly both the continuities and discontinuities over time are included in its formalization.

Still, against the background of Dewey's work, and anticipated in Sect. 2.2, one might worry that TE does not yet go far enough. Tipping the emergentist worldview over, it seems the foundations remained. The realm $R$ is not just modeled on physics and closed at any point in time, but also seems fully formed: it conceptually envelops, beforehand, any development of $S_{\mathrm{n}}$. That is to say, the novelty of the laws $\left\{L_{2}\right\}$ at $S_{2}$ is that they become "accessible" at $S_{2}$ (ibid., p. 303). They have been "barred" from $S_{1}$, "forbidden" to exist at $S_{1}$ by $\left\{L_{1}\right\}$ (ibid.). However, by subsuming any evolution of $S_{\mathrm{n}}$ under $R$, any new law did somehow pre-exist in $R$. In spite of the claim of ontological novelty, this entails considerably less novelty than claiming that the laws were not yet existing in $R$ (or that there is no $R$ ). Indeed, one might ask why there would need to be laws governing $S_{2}$ at all. The assertion that "accordingly" different laws govern $S_{2}$ assumes that from a (causally) closed realm only lawful behavior can emerge. TE can then, by its own admittance, be viewed as a reification. It is:

a reification or an ontologization of [epistemic] emergence, where qualitative novelty between successive behaviors of a given system is not to be restricted to a mere descriptive feature, but has rather to do with genuine additions to the system's ontology. (Guay and Sartenaer 2016, p. 309)

Unsurprisingly, I'm suggesting that it is not any old reification, but a selective reification. TE reifies to $R$ only the successful, predicting or determinable features of scientific (including philosophic) practices. These features are then attributed to the transformation [Tr].[Tr] embodies the premise of ontological determinism $U$ : it is a univocal and uniform determinative relationship that links the successive states of the system $S_{1}$ and $S_{2}$. I won't advocate to pull our punch and stick to epistemic emergence. That would be biting into the same a priori separation of ontology from epistemology. To allow for genuine ontological novelty, Dewey's analysis suggested, we need to drop the assumption that existence is complete. $R$ and $S_{\mathrm{n}}$ can be thought to stand in a relation of temporal reciprocity. In such a relation, as I will explain next, neither the relatum $R$ nor $S_{\mathrm{n}}$ comes ready-made but both are in the process of becoming as their relation takes shape in a multiplicity of open-ended processes of existence. These open-ended processes equally admit of stability, determinacy and lawful behavior, as well as of precariousness, indefiniteness and contingency.

\subsection{Pragmatic emergence}

Given this threat of selective emphasis what I want to draw attention to is the possibility of retaining much of the strengths of TE without either excluding or pre-supposing the precarious practices used to formulate it. I will do so by explicitly situating emergent phenomena in the processes in which they are discerned. On this view, the emergence of features in process can be captured in the following way. The process at $t_{2}\left(P_{2}\right)$ pragmatically emerges from $P_{\mathrm{s}}$ at $t_{1}$ if and only if:

$\left(\mathrm{DEP}_{p}\right) P_{2}$ is the product of a spatiotemporally continuous process going from $P_{1}$ (for example scientific practices). In particular, the "realm" $R$ to which $P_{1}$ and $P_{2}$ 
commonly belong (e.g. existence) is open, to the effect that $R$ is co-determined with each state of $P$.

$\left(\mathrm{NOV}_{p}\right) P_{2}$ exhibits new entities, properties or powers that do not exist in $P_{1}$, and that were not predicted or derived in $P_{1}$ according to the laws $\left\{L_{1}\right\}$ describing $P_{1}$.

Consider the emergence of life from physical interactions that we started this article with. Life exhibits all kinds of new behavior and properties, such as phenomenal experience and normative behavior, which we do not find in brute physical interactions. Moreover, these phenomena may well reciprocally effect the behavior of living systems such that physical laws are unable to predict them (satisfying $\mathrm{NOV}_{p}$ ). That is, $P_{1}$ seems to lack the practices, vocabulary, methods, tools, and so on, to expect such phenomena. Still we also want to say that there are practices, methods, formalizations, that allows researchers to determine the conditions historically necessary for the novel phenomena found with the advent of life (satisfying $\mathrm{DEP}_{p}$ ). In short, on this pragmatic reading, the emergence of life, and the question what existed prior to life, becomes an empirical question, not one for metaphysicians. Emergence has pragmatic criteria which are attained by the continuous development of human practices within an unfinished world.

Although this formulation of emergence, which I'll call pragmatic emergence $(\mathrm{PE})$, focuses on the practices of scientific (including philosophic) inquiry, note from the onset that it is not a retreat to epistemological emergence. Nor is it a denial of ontology. Rather, as per Dewey's suggestion, it denies the particular picture of ontology as completed. PE thus denies the very a priori distinction on which a retreat to epistemology is premised. One reason for including a 'closed realm' in TE was that it allows one to distinguish mere changes in the conditions of a system under scrutiny and genuine novelty of the system itself. There is nothing in PE that has an analogous role of fixing what counts as genuine (ontological) or apparent (epistemological) novelty beforehand. Any distinction between the system and its conditions might be made for pragmatic reasons which, reciprocally, feeds into both ontology and epistemology. In fact, one can read the proposal as an explication of how ontology and epistemology come out of the wash together in process, as I will detail in Sect. 4.1. On a pragmatic reading ontology is in formation, and any epistemologically novel state is thus also genuine ontological novelty. ${ }^{4}$

Apart from recasting TE in pragmatic terms, the most important change in this explication of emergence is the introduction of a "temporally reciprocal" relation between $P_{\mathrm{n}}$ and $R$. The temporal reciprocity between $P_{\mathrm{n}}$ and $R$ in PE means to formalize the open-endedness needed to avoid the fallacy of selective emphasis. Temporal reciprocity ensures that any determinative relationship unfolding across successive states of a given system is itself not independent of said system and becomes a metaphysical foundation, a layer of ready-made reality irrespective of time and external to process. Nonetheless PE allows for states to be successfully "linked" through "uniform and univocal" relationships. But it does so amidst of failure to connect different features,

\footnotetext{
4 This denies what Humphreys identified as the "rarity heuristic," according to which emergence should not be a common phenomenon (Humphreys 2016: 760). On the view presented here, not only is genuine ontological novelty common, but continuity is equally in need of explanation.
} 
the inability to predict or control the environment and so on. In short, the continuously unfolding of $P$ includes stability and precariousness equally. Let us look at temporal reciprocity and the other changes to emergence the above explication proposes in the next, final, section.

\section{Temporal reciprocities}

In a temporal reciprocity the mutual relation that constitutes both $R$ and $P_{\mathrm{n}}$ alike is diachronic but not merely causal (see Kirchhoff 2015). Equating a diachronic relation with causation implies a view in which the nature of the entities under consideration is already determined prior to their interaction. A diachronic and constitutive relation of temporal reciprocity by contrast considers the process of interaction the very process that determines its constituents (and for that reason is better called 'transaction,' see Dewey \& Bentley 1949, p. 103 ff.; p. 269). As a paradigmatic example of the kind of temporal reciprocity I'm looking for, consider Dewey's rendition of the reflex arc in late nineteenth century psychology (Dewey 1896; see Heft 1989; Noble 1981; Shotter 1983; Van Dijk and Rietveld 2018).

Dewey (1896) criticizes the traditional notion of the "reflex arc" for its overly causal picture of human activity. Think of a child burning its finger on a flame. The standard interpretation in Dewey's time was to say that a flame is the first stimulus, responded to by reaching for it. The next stimulus of burning is in turn followed by responding with a withdrawal of the hand. Thus, we get a causal chain of stimulus-responseinteractions. On Dewey's view, this picture however begged the question that a theory of psychology ought to be answering: the question why the flame is a "stimulus" in the first place. The flame is not a determinate stimulus that caused the withdrawal in response to it. The flame and the reaching, the burn and the withdrawal can only be distinguished as stimuli or as responses respectively in the unfolding of the entire activity.

On Dewey's account, the whole event start in the midst of coordination, of activity: "the real beginning is with the act of seeing; it is looking and not the sensation of light" (ibid., p. 358-359). One development of this activity is the burning of a finger. This burning is not a new experience "linked" by mental association to the first sensation of light, but the ongoing experience of a flame by the burning. The subsequent withdrawal "is not merely to the stimulus; it is into it" (Dewey 1896, p. 359). Over the course of the child's activity the burn develops the act of seeing, into the "seeing-of-a-lightthat-means-pain-when-contact-occurs" (Dewey 1896, p. 360; see Heft 1989). In other words, neither stimulus $\left(S_{\mathrm{s}}\right)$ nor response $\left(S_{\mathrm{r}}\right)$ (more generally: $\left.S_{\mathrm{n}}\right)$, nor the larger scale activity $(A)$, in which $S_{\mathrm{n}}$ take shape, are fully determinate. Rather they co-determine each other. One can define their relation as temporally reciprocal when meeting two conditions: a reciprocity condition (REC) and a temporality condition (TEMP) where:

(REC) $S_{\mathrm{n}}$ and $A$ codetermine each other, yet

(TEMP) $S_{\mathrm{n}}$ and $A$ unfold across different timescales.

In a temporal reciprocity both $S_{\mathrm{n}}$ and $A$ are temporally extensive processes. They are not determinate at each moment of time $\left(t_{1}, t_{2}\right)$, but determining over time. Indeed 
REC and TEMP cannot obtain if we consider either $S_{\mathrm{n}}$ or $A$ as fully formed (REC says as much). If either would be fully formed then the relation would be overdetermined (see Kim 1999). On the other hand, REC does not say that $S_{\mathrm{n}}$ and $A$ are sufficient to determine each other. Other processes are likely to enter into it. For instance, part of "seeing-of-a-light-that-means-pain-when-contact-occurs" will be the physical flame as it continues with the activity of the child. Second, it is worth pointing out that, although neither relata are fully formed, they may well be determinate to different degrees (and determine each other to different degrees). Indeed, much of $A$, the "act of seeing," the child coordinating to the flame as it starts to reach, has unfolded in a particular way already, setting up the conditions for reaching. While the reach is yet to commence and succeed or fail.

Crucially, this means that the very same activity $S_{\mathrm{r}}$ that is determining the arc from $S_{\mathrm{S}}$ is also contributing to the larger scale process of continuing $A$ (i.e. the history continued in $S_{\mathrm{s}}$ ). Recall that $A$ is forming the history that enables $S_{\mathrm{r}}$ in that very same act. The implication is that the activity $\left(S_{\mathrm{r}}\right)$ is concurrently changing its own history, or conversely: that $A$ is setting up the conditions for its own continuation (see Van Dijk and Rietveld 2018). This is what Dewey means when saying that a withdrawal is not a response to, but into the stimulus. Indeed, Dewey's (1896) main point is that $S_{\mathrm{s}}$ and $S_{\mathrm{r}}$, although successive when measured in time, are reciprocal. In this temporally reciprocal process determinacy is relative to the current activity. From inside the process, the stimulus is determined only in retrospect. As John Shotter put it, the stimulus "is only completely specified as the stimulus it is when the response to which it has been the stimulus is complete" (Shotter 1983: 27).

\subsection{Ontology from the inside}

With Dewey's rendition of the reflex arc as a paradigmatic example of temporal reciprocity (and indeed, of pragmatic emergence), let us return to pragmatic emergence and see how to cash out the temporal reciprocity I proposed between the "ontological" realm $R$ and the unfolding process $P_{\mathrm{n}}$. We can consider the successive features of the system $P_{1}$ and $P_{2}$ and the larger scale relation unfolding between them $R$ as temporally reciprocal. Specifically:

$\left(\mathrm{REC}_{t e}\right) P_{\mathrm{n}}$ and $R$ codetermine each other, yet

$\left(\mathrm{TEMP}_{t e}\right) P_{\mathrm{n}}$ and $R$ unfold across different timescales.

Like in the case of the reflex arc, neither $P_{\mathrm{n}}$ nor $R$ are determinate at any single moment in time, but are temporally extensive (in contrast to the determinative relationship $U$ ). Their reciprocity means that the very same process that determines $P_{\mathrm{n}+1}$ from $P_{\mathrm{n}}$ is also contributing to the larger scale process of determining $R$. Moreover, the history of $R$ is setting up the conditions for the continuation of $P_{\mathrm{n}}$. The implication is the continuation of $P_{\mathrm{n}}$ concurrently determines $R$. Getting back to the notion of transformative emergence, TE has been summarized as "after is different" (Guay and Sartenaer 2016: 304). If we allow for the temporal reciprocity that Dewey advocates, what comes after can determine, continue or change what came before. In PE ontological determinacy is an historical feature of the system. It is relative to ongoing, 
and still indeterminate, processes that (human) organisms are actively participating in. Ontological determinacy is established only in retrospect, on the basis of pragmatic criteria. To be sure, as human activity enters into more phenomena, domains of inquiry are differentiated, laws and mechanisms are proposed, refined and improved, but equally are others dismissed, forgotten and retracted from existence. It is ontology viewed from within, rather than outside or underlying, the processes of existence (see Costall 2004).

In carving out the landscape of emergence, Sartenaer (2016) noted that emergence looks for the middle ground between monism (only DEP) and pluralism (only NOV). A return to pragmatism, and the introduction of a temporal reciprocity that this enables, fits that spirit. PE is at once monistic and pluralistic:

The world is One just so far as its parts hang together by any definite connexion. It is many just so far as any definite connexion fails to obtain. And finally it is growing more and more unified by those systems of connexion at least which human energy keeps framing as time goes on. (James, 1907, p. 70)

Both $R$ and successive (and concurrent) states of $P$ take shape in a single relational process - but a process that is open-ended and unfinished. As such, it is "Many": it is renewed and continued multidirectionally in a manifold of singular situations. Sometimes we successfully coordinate these situations and their phenomena with each other another over time. Think for instance of CERN where skillful practices and mathematical formulations coordinate a manifold of spatiotemporally extensive activities across large constellations of people, materials and tools so that we may observe new subatomic phenomena. Or think of using biological markers, such as peptide molecules in human cerebrospinal fluid, to predict or control behavioral phenomena and impairments. As we do, and go back and forth to coordinate distinct practical domains, we're actively contributing to the continuity of the unfolding processes. In this coordination the many becomes "One": stabilizing and maintaining phenomena that thus equally enter into ontology.

The inclusion of temporally reciprocal relations secures an open-ended ontology that organisms know from within. Finally, consistent with this, pragmatic emergence does not take lawful relations, causal closure and so on, to be a necessary requirement for inclusion into reality. Rather, such hypotheses act as (historical) constraints on the way of approaching a particular part of the world. Indeed, the above formalization of PE dropped the requirement of TE that $S_{2}$, if not governed by the laws of $S_{1}$, must be governed by different laws (NOV).

In PE there may well be domains and phenomena that do not admit of lawful descriptions. Psychological phenomena might be an example (Louch 1966). These might constitutively involve normativity, practical indeterminacies and resist quantification. "Psychologists want to say" as Wittgenstein pointed out, "'There must be some law'-although no law has been found. ... Whereas to me the fact that there aren't actually any such laws seems important" (Wittgenstein 1967, p. 42). This is not to imply that we cannot ask empirical questions in psychology. We may well use lawlike descriptions to predict behavioral phenomena. But, on the view introduced here, humans can develop new, creative, risky and sometimes fruitful norms and practices by which new phenomena can be experienced because existence is unfinished, 
because ontological processes can be continued in activity. Requiring laws to govern the domains where life is lived a priori, not merely reduces but even eliminates a wide range of phenomena that may well be constitutively involved in the practice of denying them (Costall 2011; Wilcox and Katz 1984).

\section{Concluding remarks}

Prompted by the inclusion of John Dewey as an early proponent of emergentism, this article criticized standard emergentism in as far as it starts from a notion of ontology as pre-existing. By considering Dewey's fallacy of selective emphasis the paper suggested that, non-standard, transformational emergence might still show a similar ontological predilection. The suggestion in this article was to think of existence as unfinished instead. Ontology can then be thought of as temporal: as in process instead of underlying any process. Laws, regularities and causal connections are maintained in processes over a larger time scale than the transient, precarious and singular phenomena that continue them. They form in a process of becoming that equally features discontinuities, inconsistencies and indeterminacy as it unfolds.

Pragmatic emergence leads to a non-standard form of emergence in that it is diachronic and flat. It is flat because it is a non-hierarchical. By including temporally reciprocal relations it even puts the metaphysical foundations, which transformational emergence kept in place, in process. Ontological features are not given but are on the way to being given (see Ingold 2015, p. 147). Ontological determinacy is thought of as a historical feature of "unfinished processes of existence" (Dewey 1958, p. 77). In order to avoid the threat of selective emphasis Dewey reminded us throughout his writings that our abstractions and generalizations, embodied in extensive and institutionalized practices, are a starting point, not the end point of inquiry. They are neither the highest echelon of human understanding nor its metaphysical foundation. Ontology gets its determinacy by continuing our activities into the world and thus have yet more refined experience of the world.

Open-endedness and indeterminacy are at the heart of many academic fields. Such fields thus require room to emphasize different aspects of ontology from those that, say, theoretical physics might inspire. From systems biology (Oyama 2000), enactivism (Gallagher 2017; Varela et al., 1991) and branches of psychology (Costall 2004; Heft 2003; Reddy 2007; Shotter 1983; Van Dijk and Rietveld 2018) to anthropology, ethnography and science studies (Ingold 2015; Haraway 2016; Latour 1999; Tsing 2015), open-endedness is key. My hope is that, by rekindling its Deweyian past, the complex geography of emergence can find room to include one more variety. Perhaps the inclusion of a notion of emergence with an open-ended ontology will allow philosophy to enter into a fruitful exchange with a diversity of academic disciplines, framing new connections as time goes on.

Acknowledgement I am grateful to Jelle Bruineberg and Erik Myin for their insightful comments and suggestions. My thanks also to two anonymous reviewers for their valuable remarks. This research was supported by the Research Foundation Flanders (FWO, project Thinking in practice: a unified ecologicalenactive account [12V2318N]). 
Open Access This article is licensed under a Creative Commons Attribution 4.0 International License, which permits use, sharing, adaptation, distribution and reproduction in any medium or format, as long as you give appropriate credit to the original author(s) and the source, provide a link to the Creative Commons licence, and indicate if changes were made. The images or other third party material in this article are included in the article's Creative Commons licence, unless indicated otherwise in a credit line to the material. If material is not included in the article's Creative Commons licence and your intended use is not permitted by statutory regulation or exceeds the permitted use, you will need to obtain permission directly from the copyright holder. To view a copy of this licence, visit http://creativecommons.org/licenses/by/4.0/.

\section{References}

Costall, A. (2004). From Darwin to Watson (and cognitivism) and back again: The principle of animalenvironment mutuality. Behavior and Philosophy, 32, 179-195.

Costall, A. (2011). Against representationalism: James Gibson's secret intellectual debt to E.B. Holt. In E. P. Charles (Ed.), A new look at new realism: The psychology and philosophy of E.B. Holt (pp. 243-261). New Brunswick, NJ: Transaction Publishers.

Dewey, J. (1896). The reflex arc concept in psychology. The Psychological Review, 3(4), 357-370. https:// doi.org/10.1037/h0070405.

Dewey, J. (1915). The subject-matter of metaphysical inquiry. The Journal of Philosophy, Psychology and Scientific Methods, 12(13), 337-345. https://doi.org/10.2307/2013770.

Dewey, J. (1929). The quest for certainty: A study of the relation of knowledge and action. New York: Minton, Balch \& Company.

Dewey, J. (1937). Whitehead's philosophy. The Philosophical Review, 46(2), 170-177. https://doi.org/10. 2307/2180740.

Dewey, J. (1958). Experience and nature. New York, NY: Dover Publications.

Dewey, J., \& Bentley, A. F. (1949). Knowing and the known. Boston: The Beacon Press.

Emmeche, C., Køppe, S., \& Stjernfelt, F. (1997). Explaining emergence: towards an ontology of levels. Journal for General Philosophy of Science, 28(1), 83-117. https://doi.org/10.1023/A:100821612793 3.

Gallagher, S. (2017). Enactivist interventions: Rethinking the mind. Oxford, UK: Oxford University Press.

Guay, A., \& Sartenaer, O. (2016). A new look at emergence: Or when after is different. European Journal for Philosophy of Science, 6(2), 297-322. https://doi.org/10.1007/s13194-016-0140-6.

Haraway, D. J. (2016). Staying with the trouble: Making kin in the Chthulucene. Durham: Duke University Press.

Harris, R. (1981). The language myth. London: Gerald Duckworth \& Company Ltd.

Heft, H. (1989). Affordances and the body: An intentional analysis of Gibson's ecological approach to visual perception. Journal for the Theory of Social Behaviour, 19(1), 1-30. https://doi.org/10.1111/j. 1468-5914.1989.tb00133.x.

Heft, H. (2003). Affordances, dynamic experience, and the challenge of reification. Ecological Psychology, 15(2), 149-180. https://doi.org/10.1207/S15326969ECO1502_4.

Humphreys, P. (1997). Emergence, not supervenience. Philosophy of science, 64, S337-S345. https://doi. org/10.1086/392612.

Humphreys, P. (2016). Emergence. In P. Humphreys (Ed.), Oxford handbook of philosophy of science. New York: Oxford University Press.

Ingold, T. (1993). The art of translation in a continuous world. In G. Pálsson (Ed.), Beyond boundaries: Understanding, translation and anthropological discourse (pp. 210-230). Oxford: Berg.

Ingold, T. (2015). The life of lines. Abingdon: Routledge.

James, W. (1890). The principles of psychology. New York, NY: Dover Publications.

James, W. (1907/2000). Pragmatism and other writings. London, UK: Penguin Classics.

Kim, J. (1999). Making sense of emergence. Philosophical Studies, 95(1), 3-36. https://doi.org/10.1023/ A: 1004563122154

Kim, J. (2002). The layered model: Metaphysical considerations. Philosophical Explorations, 5(1), 2-20. https://doi.org/10.1080/10002002018538719. 
Kirchhoff, M. D. (2015). Extended cognition and the causal-constitutive fallacy: In search for a diachronic and dynamical conception of constitution. Philosophy and Phenomenological Research, 90(2), 320-360. https://doi.org/10.1111/phpr.12039.

Latour, B. (1999). Pandora's hope: Essays on the reality of science studies. Cambridge: Harvard University Press.

Louch, A. R. (1966). Explanation and human action. Berkeley: University of California Press.

Noble, W. G. (1981). Gibsonian theory and the pragmatist perspective. Journal for the Theory of Social Behaviour, 11, 65-85. https://doi.org/10.1111/j.1468-5914.1981.tb00023.x.

Oyama, S. (2000). The ontogeny of information: Developmental systems and evolution (2nd ed.). New York: Cambridge University Press.

Reddy, V. (2007). Getting back to the rough ground: Deception and 'social living'. Philosophical Transactions of the Royal Society B: Biological Sciences, 362(1480), 621-637. https://doi.org/10.1098/rstb.2 006.1999.

Sawyer, R. K. (2002). Emergence in psychology: Lessons from the history of non-reductionist science. Human Development, 45(1), 2-28. https://doi.org/10.1159/000048148.

Sartenaer, O. (2015). Synchronic vs diachronic emergence: A reappraisal. European Journal for Philosophy of Science, 5(1), 31-54. https://doi.org/10.1007/s13194-014-0097-2.

Sartenaer, O. (2016). Sixteen years later: Making sense of emergence (again). Journal for General Philosophy of Science, 47(1), 79-103. https://doi.org/10.1007/s10838-015-9312-x.

Shaw, R. E., \& Turvey, M. T. (1999). Ecological Foundations of Cognition II. Degrees of Freedom and Conserved Quantities in Animal-Environment Systems. Journal of Consciousness Studies 6 (11-12), 111-123.

Shotter, J. (1983). "Duality of structure" and "intentionality" in an ecological psychology. Journal for the Theory of Social Behaviour, 13, 19-44. https://doi.org/10.1111/j.1468-5914.1983.tb00460.x.

Tsing, A. (2015). The mushroom at the end of the world: On the possibility of life in capitalist ruins. Princeton: Princeton University Press.

Van Dijk, L. (2016). Laying down a path in talking. Philosophical Psychology, 29(7), 993-1003. https:// doi.org/10.1080/09515089.2016.1213379.

Van Dijk, L., \& Rietveld, E. (2018). Situated anticipation. Synthese, 5, 1-23. https://doi.org/10.1007/s112 29-018-02013-8.

Varela, F. J., Thompson, E., \& Rosch, E. (1991). The embodied mind. Cambridge: MIT Press.

Whitehead, A. N. (1925). Science and the modern world. New York: The Free Press.

Wilcox, S., \& Katz, S. (1984). Can indirect realism be demonstrated in the psychological laboratory? Philosophy of the Social Sciences, 14(2), 149-157. https://doi.org/10.1177/004839318401400202.

Wittgenstein, L. (1958). The blue and brown books. Oxford, UK: Blackwell Publishing.

Wittgenstein, L. (1967). Lectures and conversations on aesthetics, psychology and religious belief. Berkeley: University of California Press.

Publisher's Note Springer Nature remains neutral with regard to jurisdictional claims in published maps and institutional affiliations. 